\title{
The effect of maternal obesity on the course of labor
}

\section{Maribelle Verdiales, Carlos Pacheco and Wayne R. Cohen*}

Departments of Obstetrics and Gynecology, Jamaica Hospital Medical Center and the Weill Cornell Medical College, New York City, USA

\begin{abstract}
Aim: To determine whether maternal obesity is associated with dysfunctional labor patterns.

Methods: In a case-control design we compared the graphic labor patterns of a group of 105 very obese subjects [body mass index (BMI) $>35 \mathrm{~kg} / \mathrm{m}^{2}$ ] with those of 113 lean controls $\left(\mathrm{BMl}<26 \mathrm{~kg} / \mathrm{m}^{2}\right)$. All entered spontaneous labor at term. Cases with birth weights $>4 \mathrm{~kg}$, diabetes mellitus, hypertension and prior cesarean delivery were excluded.

Results: The obese group had a significantly higher frequency of arrest of dilatation (17.6 vs. $5.2 \%$; $P=0.005)$.

Conclusions: Maternal obesity is associated with active phase labor dysfunction, specifically arrest of dilatation.
\end{abstract}

Keywords: Body mass index (BMI); dysfunctional labor; labor; maternal obesity.

\section{Introduction}

The current epidemic of obesity in the developed world has adversely affected public health in many ways. It has contributed to the prevalence and severity of medical conditions including diabetes mellitus, hypertension, heart disease, and certain types of cancer [20]. It has also created reproductive adversity. Many obesity-related illnesses complicate pregnancies. Moreover, maternal obesity is associated with excess fetal growth, which increases the likelihood of cesarean section and of birth injury, as well as potential life-long health risks [11].

Many studies have demonstrated a strong relationship between maternal obesity and the risk of cesarean delivery $[1,5,7,10,13-17,19,23]$. The reasons for this high

\footnotetext{
*Corresponding author:

Wayne R. Cohen, MD

Jacobi Medical Center

Room 1 S22

1400 Pelham Parkway South

Bronx

New York 10461

USA

Tel.: + 1-718-918-4567

Fax: +1-718-975-5668

E-mail: Wayne.cohen@nbhn.net; gynherp@yahoo.com
}

cesarean rate are, however, not entirely clear. It relates in part to the association of obesity with diabetes and hypertension [14], which themselves predispose to the need for cesarean. In addition, the high prevalence of fetal macrosomia [1, 9, 16, 23, 26] among obese women probably leads to more cesareans for cephalopelvic disproportion. These factors do not, however, explain completely the high obesity-related cesarean rate noted in most studies. High cesarean rates have been found in otherwise low-risk obese women [8, 26], and multivariate analyses support obesity as an independent risk factor associated with cesarean delivery $[17,18]$. A possible explanation is that obesity might somehow create dysfunctional labor, independent of the presence of true fetopelvic disproportion.

To enhance our understanding of the association between maternal obesity and labor progress, we studied graphic labor patterns in a group of very obese women and compared them to those of lean controls. We hypothesized that maternal obesity affects the likelihood of an arrest of dilatation, and other objectifiable labor abnormalities.

\section{Methods}

This retrospective case-control study qualified for expedited review from Jamaica Hospital Medical Center's Institutional Review Board. Our goal was to compare the labors of a group of very obese women [body mass index (BMI) $>35 \mathrm{~kg} / \mathrm{m}^{2}$ ] with those of a control group with a normal BMI $\left(<26 \mathrm{~kg} / \mathrm{m}^{2}\right)$. Both groups would consist of term singleton pregnancies without neonatal macrosomia, diabetes, or other complications. These exclusions eliminated most of the factors associated with obesity known to increase the risk of dysfunctional labor.

We estimated a sample size of 200 would be necessary to have a power of 0.80 to detect a three-fold increase in the frequency of arrest of dilatation with an alpha of 0.05. Based on our hospital's known prevalence of macrosomia, diabetes mellitus, multiple gestations and preterm deliveries, we estimated that about 400 cases would be necessary to provide 200 cases for analysis after exclusions.

To constitute the groups of cases and controls, we used our electronic medical record (E\&C Medical Intelligence Inc., New York, NY) to identify the first 200 consecutive obstetric cases with a maternal $\mathrm{BMI}>35 \mathrm{~kg} / \mathrm{m}^{2}$ and 200 consecutive normal weight cases (BMl $<26 \mathrm{~kg} / \mathrm{m}^{2}$ ) beginning in October 2003. From these, we excluded multiple gestations, cases with birth weight $>4000 \mathrm{~g}$ or gestational age $<37$ completed weeks, intrauterine growth restriction, diabetes mellitus, severe hypertension or preeclampsia, and major fetal anomalies. We also excluded all inductions of labor, patients with a prior cesarean, and cases delivered by cesarean prior to labor. Of the remaining 254 cases 
we eliminated 36 in which the records had insufficient data about labor progress to allow graphic analysis. Remaining after these exclusions were 105 obese and 113 lean cases. Thus, the case and control groups consisted of uncomplicated term pregnancies with spontaneous labors. The cases were very obese and the controls lean. The goal of this selection process was to isolate the effects of obesity per se on the course of labor.

Pertinent data regarding labor and delivery were abstracted from the medical records of all cases. Examinations of cervical dilatation and fetal station were plotted on a graph by one of the investigators, blinded to whether the patient was lean or obese. The resulting curves of cervical dilatation and fetal descent were analyzed, and labor dysfunctions classified according to the method of Friedman [6]. Labor dysfunctions are defined in Appendix 1. Data were entered into a statistical software system (JMP, version 5.0; SAS Statistical Software, Cary, NC) for analysis. Differences between the two groups were sought with $\chi^{2}$ testing for categorical variables and Student's $t$-test for continuous variables. In instances in which expected cell numbers for categorical data were $<5$, Fisher's exact test was used. For continuous data that were not normally distributed (such as quantifiable labor variables) the non-parametric Mann-Whitney test was used.

\section{Results}

The characteristics of the two groups are summarized in Table 1. The obese patients were significantly older by about 2 years than the lean ones. The proportion of nulliparas, the cesarean rate (for all indications), and the use of oxytocin were similar in both groups. There were no operative deliveries. While the mean birth weight in the obese group was significantly larger than in the lean group $(P=0.012)$ the mean difference was only $116 \mathrm{~g}$, and the proportion of larger babies (3700-3999 g) was not significantly different between the two groups.

The quantifiable characteristics of the labors in the lean and obese cases were generally similar (Table 2). Exceptions were a significantly shorter latent phase, which accounted for the shorter first stage of labor among obese nulliparas.

When labor curves were analyzed for dysfunctional labor patterns, however, significant differences were found between the two groups (Table 3). While obese patients had a lower frequency of prolonged latent phase, they had a dramatically greater incidence of arrest of dilatation ( 17.6 vs. $5.2 \%, \mathrm{P}=0.005$ ). In addition, there were more patients in the obese group with protracted active phase (14.8 vs. $9.3 \%, P=0.177)$ and protracted descent (3.3 vs. $0 \%, P=0.180$ ), although these differences did not reach statistical significance.

\section{Discussion}

We found a significantly higher rate of arrest of dilatation in obese when compared to lean women. We considered that the greater birth weight in the obese cases might have contributed to the higher rate of arrest disorders, even though the difference of only $116 \mathrm{~g}$ seems unlikely to have had a major impact on the probability of cephalopelvic disproportion. The proportion of larger babies (3700-3999 g) was not different between the groups.

Table 1 Characteristics of the sample.

\begin{tabular}{|c|c|c|c|}
\hline & $\begin{array}{l}\text { Lean } \\
(n=113)\end{array}$ & $\begin{array}{l}\text { Obese } \\
(n=105)\end{array}$ & P-value \\
\hline Body mass index (kg/m²) & $24.0 \pm 1.6$ & $39.7 \pm 4.8$ & $<0.001$ \\
\hline Maternal age (years) & $24.4 \pm 5.5$ & $26.3 \pm 6.5$ & 0.020 \\
\hline Nulliparity (\%) & 60 & 51 & 0.190 \\
\hline Cesarean rate (\%) & 8.0 & 10.5 & 0.640 \\
\hline Oxytocin use (\%) & 35 & 30 & 0.340 \\
\hline Birth weight 3700-3999 g, n (\%) & $7(6.0)$ & $9(9.0)$ & 0.680 \\
\hline
\end{tabular}

Table 2 Quantifiable labor characteristics*.

\begin{tabular}{|c|c|c|c|c|}
\hline & \multicolumn{2}{|l|}{ Lean $(n=113)$} & \multicolumn{2}{|l|}{ Obese $(n=105)$} \\
\hline & Nulliparas & Multiparas & Nulliparas & Multiparas \\
\hline Latent phase (min) & $735(333,1617)$ & $330(156,1093)$ & $540(153,1062)^{\star \star}$ & $330(153,1068)$ \\
\hline Active phase (min) & $177(95,394)$ & $107(59,270)$ & $143(68,471)$ & $90(48,198)$ \\
\hline Stage I (min) & $937(484,1801)$ & $487(264,1094)$ & $665(218,1198)^{\star \star}$ & $359(164,1225)$ \\
\hline Stage II (min) & $30(8,111)$ & $14(4,40)$ & $32(11,139)$ & $10(2,55)$ \\
\hline Deceleration phase (min) & $60(25,148)$ & $30(9,124)$ & $50(10,164)$ & $28(10,84)$ \\
\hline Slope dilatation $(\mathrm{cm} / \mathrm{h})$ & $2.9(0.9,6.1)$ & $4.2(2.0,10.0)$ & $3.5(0.9,7.0)$ & $4.8(1.8,12.2)$ \\
\hline Slope descent $(\mathrm{cm} / \mathrm{h})$ & $6.2(2.7,17.2)$ & $15.5(5.1,44.5)$ & $6.0(1.6,24.4)$ & $17.8(4.8,49.4)$ \\
\hline
\end{tabular}

${ }^{*}$ All values are median $\left(10^{\text {th }}, 90^{\text {th }}\right.$ percentile).

${ }^{*}$ Significantly different from lean group of same parity. 
Table 3 Dysfunctional labor patterns.

\begin{tabular}{llll}
\hline & Lean & Obese & P-value \\
\hline $\begin{array}{l}\text { Prolonged latent phase } \\
\mathrm{n} / \text { total }^{*}(\%)\end{array}$ & $12 / 65(18.5)$ & $5 / 74(6.8)$ & $<0.001$ \\
$\begin{array}{l}\text { Protracted active phase } \\
\mathrm{n} / \text { total (\%) }\end{array}$ & $9 / 97(9.3)$ & $13 / 88(14.8)$ & 0.177 \\
$\begin{array}{l}\text { Arrest of dilatation } \\
\mathrm{n} / \text { total (\%) }\end{array}$ & $5 / 96(5.2)$ & $16 / 91(17.6)$ & 0.005 \\
$\begin{array}{l}\text { Prolonged deceleration phase } \\
\mathrm{n} / \text { total (\%) }\end{array}$ & $12 / 89(13.5)$ & $9 / 90(10.0)$ & 0.180 \\
$\begin{array}{l}\text { Failure of descent } \\
\mathrm{n} / \text { total (\%) }\end{array}$ & $1 / 102(1.0)$ & $0 / 92(0)$ & 0.526 \\
$\begin{array}{l}\text { Protracted descent } \\
\mathrm{n} / \text { total (\%) }\end{array}$ & $0 / 100(0)$ & $3 / 89(3.3)$ & 0.108 \\
$\begin{array}{l}\text { Arrest of descent } \\
\mathrm{n} / \text { total (\%) }\end{array}$ & $5 / 103(4.9)$ & $1 / 91(1.1)$ & 0.137 \\
\hline
\end{tabular}

${ }^{*}$ Total cases in each cell vary because in some cases an insufficient number of dilatation or descent measurements were documented in the medical record to allow definitive diagnosis.

Moreover, among cases with birth weights below $3500 \mathrm{~g}$, in which disproportion would be uncommon, there were $5.0 \%$ of lean women who had arrest of dilatation, compared with $18.8 \%$ of the obese cases $(P=0.002)$. The birth weights among the cases with arrest of dilatation were slightly, but not significantly, lower than those of the lean controls with arrest disorders (3396 \pm 273 vs. $3280 \pm 265 \mathrm{~g} ; \mathrm{P}=0.399$ ). We conclude that the nearly three-fold higher frequency of arrest of dilatation was not explainable by the small difference in birth weight between the two groups.

Maternal age is another potential confounder, because older women are more likely to have dysfunctional labor patterns [3], but the difference of only 2 years in the mean age of the groups is unlikely to explain the observed difference in dysfunctional labor. Moreover, in subjects with arrest of dilatation, we found no difference in maternal age. In fact, the lean cases with arrest were slightly older ( 25.4 vs. 24.6 years; $P=0.804)$. Thus, it is improbable that the observed difference in arrest of dilatation observed in the obese patients is due to higher birth weights or older maternal age among them.

Although there were more protracted active phase disorders in the obese group (14.8 vs. 9.3\%) this difference was not statistically significant. The difference could have been muted by the fact that there were more nulliparas in the lean group, and nulliparas would be expected to have substantially more protraction disorders than multiparas [6]. The failure to find a significant difference could also have been a type II error, in that a sample size of $>500$ cases would have been necessary to have $80 \%$ power to detect a doubling in the frequency of protracted active phase.

There was no significant difference in the frequency of disorders of the pelvic division of labor (prolonged deceleration phase, failed, arrested or protracted descent), suggesting that the observed effects of obesity were confined to the first stage, and did not influence abnormalities of descent. Second stage abnormalities are more closely linked to bony disproportion than are active phase disorders, which more often are associated with deficient contractility. If obesity impairs contractility, it makes sense that its effects would be observed primarily in the first stage.

Consistent with this notion are the observations of Buhimschi et al., who showed no difference in intrauterine pressures generated during the second stage among groups of obese, overweight, and normal weight women [2].

Our finding of fewer latent phase disorders in obese nulliparas seems inconsistent with the hypothesis that obesity hinders contractility. However, the actual median difference in latent phase duration was small (about $2 \mathrm{~h}$ ) and may not be clinically meaningful. The length of the latent phase is especially difficult to ascertain from this kind of retrospective analysis, because of the unavoidable subjectivity in identifying the onset of labor. By contrast, active phase slopes and patterns of dilatation are readily determinable from most records.

Other clinical evidence is in harmony with the potential for obesity to compromise the intensity or efficiency of uterine contractility. Onset of labor may be delayed by obesity, and dysfunctional labor may be abetted. Obese women have been observed to have longer-term gestations, and more post-dates pregnancies than thinner women [4, 22]. Also, in a prior analysis of labor duration, Vahratian et al. studied rates of dilatation in a data base of 612 nulliparas and found active phase labor (defined as $4-10 \mathrm{~cm}$ dilatation) was significantly longer in overweight and obese women, after adjusting for birth weight [24]. Zhang et al. [27] showed in a clinical study that obese women had a higher risk of cesarean, related primarily to abnormal progress in the first stage of labor.

Until recently, there has been no biologic basis to explain why simply being obese would affect labor, but accumulating evidence supports the association of obesity with impaired uterine contractility. In one study, myometrial tissue obtained at cesarean from obese 
women was shown in vitro to contract with less force (as indicated by lower calcium fluxes) than those from normal weight subjects [27].

The basis for this contractile inhibition may reside in some of the biochemical changes induced by obesity. For example, leptin, a protein with diverse metabolic and regulatory functions, is produced in increased amounts in obese individuals. Moynihan et al. demonstrated that leptin strongly inhibited myometrial contractility in vitro [12]. Cholesterol, also increased in obesity, has similar inhibitory effects on myometrial activity and calcium signaling [21, 28].

We conclude that obesity may interfere with the progress of labor, resulting in dysfunctional patterns of dilatation. The mechanism for such an effect may be mediated through diminished uterine contractility in the active phase of labor, a consequence of increased levels of leptin, cholesterol, or other metabolic features of the obese state. Obesity should be added to the list of possible causes of abnormal labor progression.

The implications of our findings are considerable because of the rising prevalence of obesity in the pregnant population. Obstetricians should be aware that dysfunctional labor patterns in the first stage may be attributable to compromised contractility in these patients, and not necessarily a consequence of disproportion. The fact, however, that obesity does predispose to fetal macrosomia can make this a challenging clinical decision. Whether the presumed effects of obesity on uterine contractility can be readily overcome by the use of oxytocin is unknown and requires study.

Despite the convincing difference we found in the frequency of arrest of dilatation, our study was not sufficiently powered to demonstrate with confidence differences in other dysfunctional labor patterns. The sample, however, had the advantage over large data bases in that it was subject to meticulous review of the clinical details of every record, so we are confident of the accuracy of the labor diagnoses and other clinical information. Unfortunately, no meaningful information about uterine activity could be gleaned from the records, because intrauterine pressure catheters were used infrequently in the study institution. Therefore, we can only speculate about the mechanism that underlies our findings.

In summary, we demonstrated a more than three-fold higher rate of arrest of dilatation among very obese women compared to those who were lean. Interference with normal progress of labor may therefore be among the many adverse health consequences of marked obesity. The mechanism underlying this observation is not known, but may be related to the effects of obesity on uterine contractility.

\section{Appendix 1. Definitions of labor terms $[6,25]$}

Labor curve: A plot of the relationships among cervical dilatation, fetal station, and elapsed time in labor.
Latent phase: Portion of labor from onset until the acceleration in cervical dilatation seen at onset of active phase.

Active phase: Portion of labor from end of latent phase to full cervical dilatation.

Deceleration phase: The terminal portion of active phase dilatation when the cervix is approaching the widest diameter of the presenting part. Generally this occurs between about $8 \mathrm{~cm}$ and full dilatation.

Prolonged latent phase: Exceeds $20 \mathrm{~h}$ in nulliparas or $14 \mathrm{~h}$ in multiparas.

Protracted active phase: Linear dilatation in active phase $<1.2 \mathrm{~cm} / \mathrm{h}$ in nulliparas or $<1.5 \mathrm{~cm} / \mathrm{h}$ in multiparas.

Arrest of dilatation: No progress in dilatation for $2 \mathrm{~h}$ in active phase labor.

Prolonged deceleration phase: Exceeds $3 \mathrm{~h}$ in nulliparas or $1 \mathrm{~h}$ in multiparas.

Failure of descent: No descent of the head from early labor to beyond the onset of deceleration phase or second stage.

Protracted descent: Head descent in second stage $<1 \mathrm{~cm} / \mathrm{h}$ in nulliparas or $2 \mathrm{~cm} / \mathrm{h}$ in multiparas.

\section{References}

[1] Barau G, Robillard P-Y, Hulsey TC, Dedecker F, Laffte A, Gérardin P, et al. Linear association between maternal prepregnancy body mass index and risk of caesarean section in term deliveries. Br J Obstet Gynaecol. 2006;113:11737.

[2] Buhimschi CS, Buhimschi IA, Malinow AM, Weiner CP. Intrauterine pressure during the second stage of labor in obese women. Obstet Gynecol. 2004;103:225-30.

[3] Cohen WR, Newman L, Friedman EA. Frequency of labor disorders with advancing maternal age. Obstet Gynecol. 1980;55:414-6.

[4] Denison FC, Price J, Graham C, Wild S, Liston WA. Maternal obesity, length of gestation, risk of postdates pregnancy and spontaneous onset of labour at term. $\mathrm{Br} \mathrm{J}$ Obstet Gynaecol. 2008;115:720-5.

[5] Ducarme G, Rodrigues F, Aissaoui F, Davitian C, Pharisien I, Uzan M. Grossesse des patientes obèses: quels risques faut-il craindre? Gynecol Obstet Fertil. 2007;35:19-24.

[6] Friedman EA. Labor: clinical evaluation and management. 2nd ed. New York (NY): Appleton-Century-Crofts; 1978.

[7] Hamon C, Fanello S, Catala L, Parot E. Conséquences de l'obésité maternelle sur le déroulement du travail et l'accouchement: A l'exclusion des autres pathologies pouvant modifier la prise en charge obstétricale. J Gynecol Obstet Biol Reprod. 2005;34:109-14.

[8] Kaiser PS, Kirby RS. Obesity as a risk factor for cesarean in a low-risk population. Obstet Gynecol. 2001;97:39-43.

[9] Kliegman RM. Perinatal problems of the obese mother and her infant. Obstet Gynecol. 1985;66:299-306.

[10] Lynch CM, Sexton DJ, Hession M, Morrison JJ. Obesity and mode of delivery in primigravid and multigravid women. Am J Perinatol. 2008;25:163-8.

[11] McMillen IC, MacLaughlin SM, Muhlhausler BS, Gentili S, Duffield JL, Morrison JL. Developmental origins of adult 
health and disease: the role of periconceptional and foetal nutrition. Basic Clin Pharmacol Toxicol. 2008;102:82-9.

[12] Moynihan AT, Hehir MP, Glavey SV, Smith TJ, Morrison JJ. Inhibitory effect of leptin on human uterine contractility in vitro. Am J Obstet Gynecol. 2006;196:504-9.

[13] Murphy DJ, Liebling RE, Verity L, Swingler R, Patel R. Early maternal and neonatal morbidity associated with operative delivery in second stage of labour: a cohort study. Lancet. 2001;358:1203-7.

[14] Perlow JH, Morgan MA, Montgomery D, Towers CV, Porto M. Perinatal outcome in pregnancy complicated by massive obesity. Am J Obstet Gynecol. 1992;167:968-72.

[15] Robinson HE, O'Connell CM, Joseph KS, McLeod NL. Maternal outcomes in pregnancies complicated by obesity. Obstet Gynecol. 2005;106:1357-64.

[16] Rode L, Nilas L, Wojdemann K, Tabor A. Obesity-related complications in Danish single cephalic term pregnancies. Obstet Gynecol. 2005;105:537-42.

[17] Roman H, Goffinet F, Hulsey TF, Newman R, Robillard PY, Hulsey TC. Maternal body mass index at delivery and risk of caesarean due to dystocia in low risk pregnancies. Acta Obstet Gynecol. 2008;87:163-70.

[18] Sheiner E, Levy A, Menes TS, Silverberg D, Katz M, Mazor M. Maternal obesity as an independent risk factor for caesarean delivery. Paed Perinat Epidemiol. 2004;18:196201.

[19] Shepard MJ, Saftlas AF, Leo-Summers L, Bracken MB. Maternal anthropometric factors and risk of primary cesarean delivery. Am J Public Health. 1998;88:1534-8.

[20] Sjostrom LV. Mortality of severely obese subjects. Am J Clin Nutr. 1992;55(Suppl 2):516S-23S.

[21] Smith RD, Babiychuk EB, Noble K, Draeger A, Wray S. Increased cholesterol decreases uterine activity: functional effects of cholesterol alteration in pregnant rat myometrium. Am J Cell Physiol. 2005;288:C982-88.

[22] Stotland NE, Washington AE, Caughey AB. Prepregnancy body mass index and the length of gestation at term. Am J Obstet Gynecol. 2007;197:378.e1-378.e5.

[23] Sukalich S, Mingione MJ, Glantz C. Obstetric outcomes in overweight and obese adolescents. Am J Obstet Gynecol. 2006;195:851-5.

[24] Vahratian A, Zhang J, Troendle JF, Savitz DA, Siega-Riz. Maternal prepregnancy overweight and obesity and the pattern of labor progression in term nulliparous women. Obstet Gynecol. 2004;104:943-51.

[25] Weizsaecker K, Deaver J, Cohen WR. Labour characteristics and neonatal Erb's palsy. Br J Obstet Gynaecol. 2007;114:1003-9.

[26] Young TK, Woodmansee B. Factors that are associated with cesarean delivery in a large private practice: the importance of prepregnancy body mass index and weight gain. Am J Obstet Gynecol. 2002;187:312-20.

[27] Zhang J, Bricker L, Wray S, Quenby S. Poor uterine contractility in obese women. Br J Obstet Gynaecol. 2007;14: 343-8.

[28] Zhang J, Kendrick A, Quenby S, Wray S. Contractility and calcium signaling of human myometrium are profoundly affected by cholesterol manipulation: Implications for labor? Reprod Sci. 2007;14:456-66.

The authors stated that there are no conflicts of interest regarding the publication of this article.

Received January 27, 2009. Revised April 15, 2009. Accepted May 4, 2009. Previously published online July 10, 2009. 